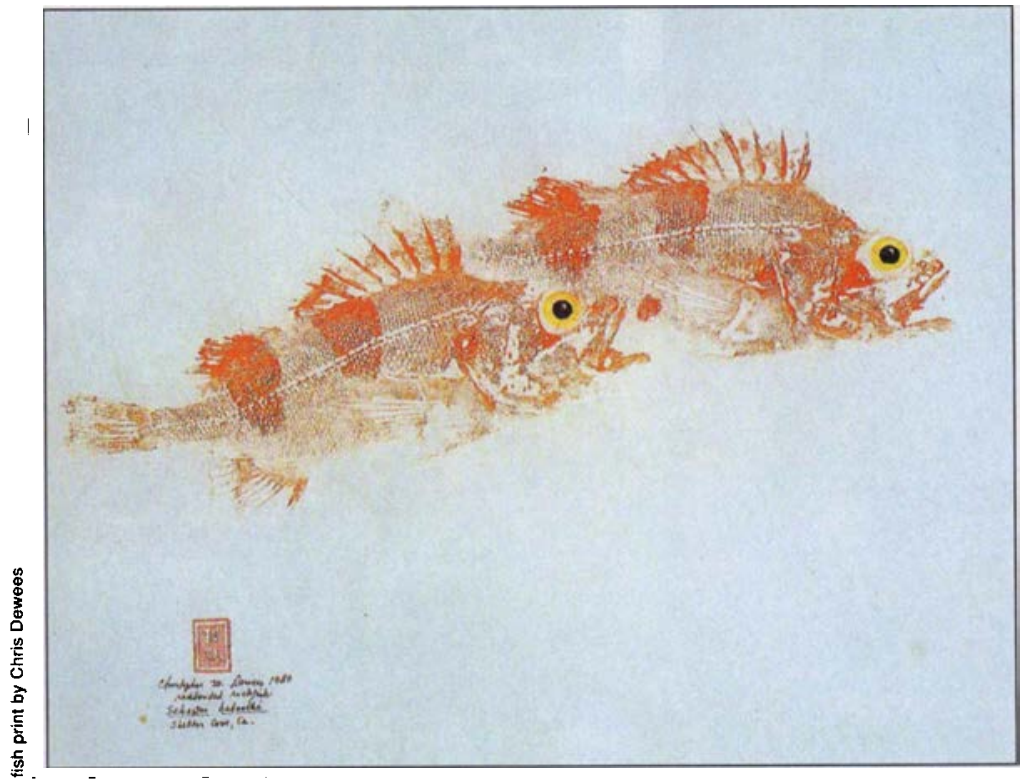

To limit mortality from fishing in California, some species of rockfish are managed with both fleetwide quotas for the entire season and with trip limits for each vessel to spread the catch out over a longer time period. The recreational fishery for rockfish is managed with daily bag limits (currently 15 fish).

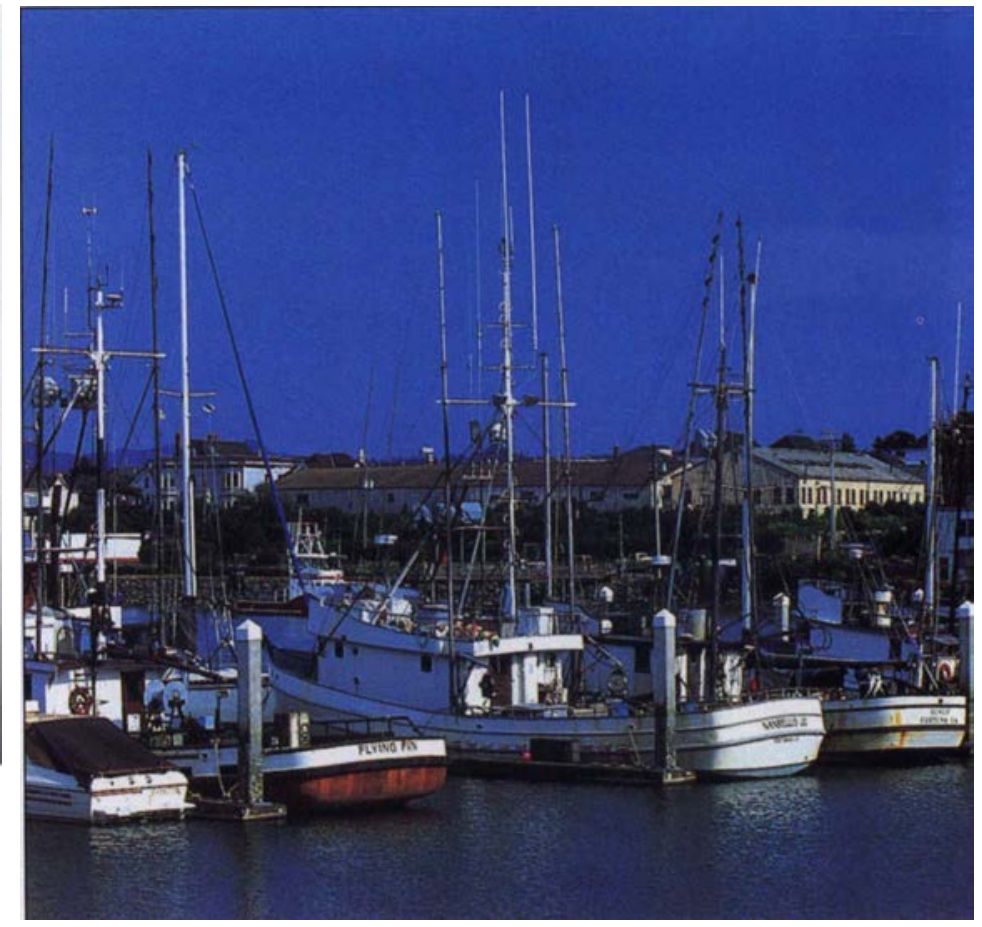

Increased fishing pressure and habitat degradation are among factors causing declines in some fish populations.

\section{Sustaining ocean fisheries poses challenge for resource managers}

\author{
Christopher M. Dewees
}

\begin{abstract}
California is one of the world's most productive and intensely harvested marine fisheries areas. Increased fishing, habitat degradation, expanding human population and decreases in water quality and quantity have put great stress on the state's coastal marine resources. Research and extension activities funded by California Sea Grant, DANR and the California Resources Agency focus on improving the methods and policies needed to manage fisheries. Significant changes in the way we manage these resources are likely to occur in the 21st century.
\end{abstract}

Tn recent years the news media have Leen filled with reports of fishery collapses and fishery problems around the world: the closure of the cod fishery off New England and the Canadian Maritimes, and the listing of some Pacific Coast salmon runs under the Endangered Species Act. These events have led to significant social and economic turmoil in communities that rely on natural resources.

At the same time, there is such a market glut of some species of salmon from Alaska that salmon prices have plummeted to such a level that the fish are given away to food banks. Also, in recent years, squid landings in California have skyrocketed. This presents a confusing picture of the state of fisher- ies and brings home the realization that fisheries are dynamic, complex and difficult to manage on a sustainable basis.

Harvesting wild fish and shellfish has historically been important for subsistence and commerce. Except for some local depletions, primarily of shellfish, overharvesting was seldom a problem until modern fisheries developed over the past 150 years. Many, including the influential British scholar Thomas Huxley during the 1880 s, believed that the major ocean fisheries were inexhaustible. As recently as the 1960s, many people felt that the oceans would be the answer to world hunger.

Events of the past quarter-century, such as the explosion of improved technology enabling more efficient harvesting, globalization of markets, improved transportation and seafoodhandling techniques, and increased demand for seafood have made it clear that the sea is not inexhaustible. World fish catches peaked in 1989 at about 89 million tons and are declining. The challenge facing fisheries managers is how to stop these declines and maintain healthy sustainable fisheries (see page 28).

continued on p. 29 


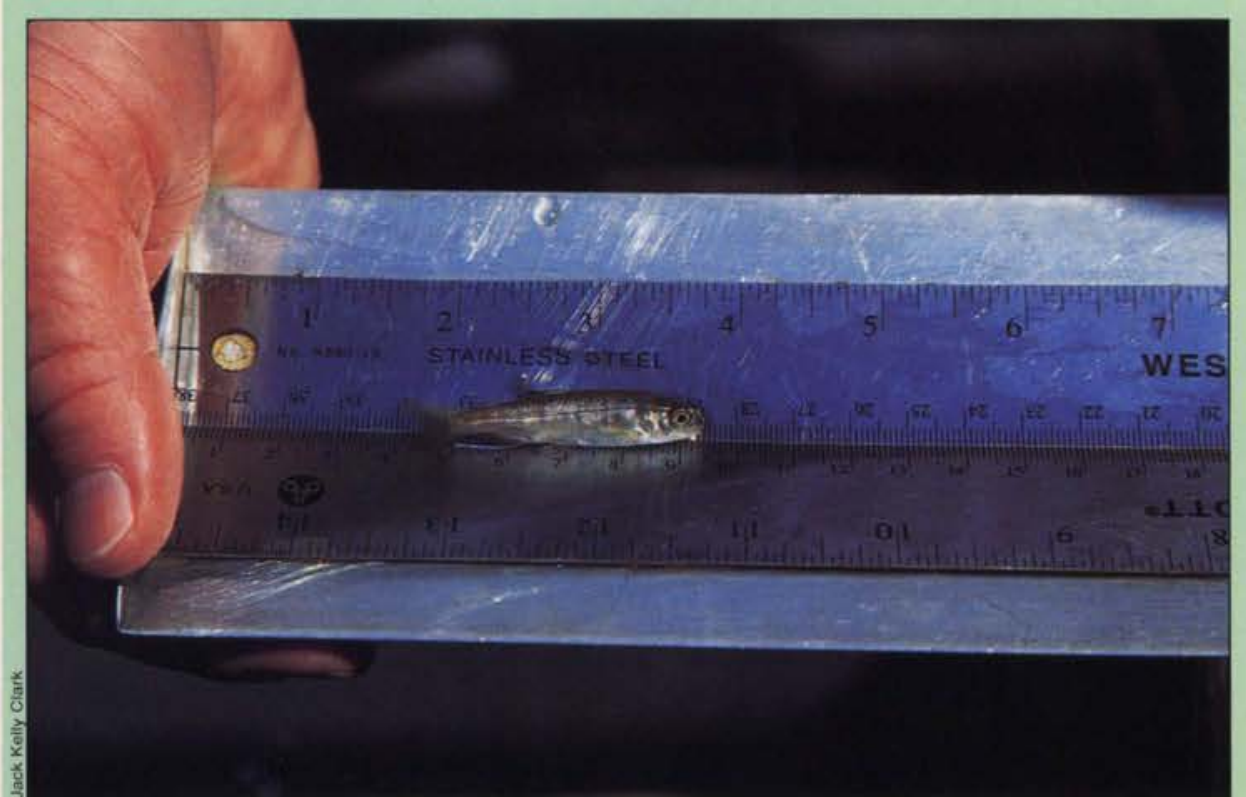

Samples of juvenile salmon and steelhead are netted out of the creek and measured to determine growth rates.

Although monitoring adult spawning salmon is a good way to gauge stock health, the real key to the health of salmonid habitat is juvenile salmon (smolt) production. During the past 5 years, Rellim biologists and I have monitored juvenile coho and chinook salmon production and compared it to adult spawning escapement. The results are just beginning to show a system in biological balance that can withstand fluctuations in adult returns and changing environmental conditions.

Restoring salmon habitat and increasing production also require educating landowners, enhancement groups and the public - those who will be responsible for covering the "costs" of improving and restoring salmon resources. In 1983, Northern California Sea Grant advisors organized the first statewide enhancement conference, which functioned as a valuable source of information about technical needs and project funding sources. These conferences continue as a primary information outreach to community-based restoration groups with guidance from the Salmonid Restoration Federation.

Extension Sea Grant staff have also coordinated programs for the SpringRun Chinook Salmon Workgroup on the Sacramento River. Habitat improvement actions taken by this group of farmers, landowners, fishers, forest managers, irrigation districts, environmentalists and resource agencies have delayed a potential Endangered Species Act (ESA) listing of this stock.

The recent and potential listings of salmon and steelhead species under the Federal ESA have brought home the need for community cooperation in restoring salmonid habitat and healthy stocks. Not only are these resources important to the economic viability of many communities, they are also symbols of our commitment to a healthy environment and biodiversity.

J. Waldvogel is the California/Oregon Sea Grant Extension Advisor, Del Norte and Curry counties.

\section{Further Reading}

Howard C. 1994. Juvenile Salmonid Monitoring on the East/West Branches of Mill Creek. Rellim Redwood Company Technical Report. $25 \mathrm{p}$.

Toole C. Waldvogel J. (eds.). 1989-1994. Proceedings of the 7 th-12th Salmonid Restoration Conferences. UC Cooperative Extension.

Waldvogel J. 1988. Fall Chinook Salmon Spawning Escapement Estimate for a Tributary of the Smith River, California. Second Interim Report (1980-87), UCSGEP-88-5. $22 \mathrm{p}$. continued from $p .27$

Over the past 25 years since the creation of Sea Grant, U.S. fisheries have moved from a development and Americanization phase to the current focus on issues of sustainability, ecosystem management, globalization, overcapitalization, bycatch of nontarget species, comanagement and allocation among user groups. Similarly, there has been a transition in Sea Grant research and extension focus from increasing fishers' production to concentrating on management-related issues. The commercial and recreational fishing industry, fishery managers, conservation organizations and concerned citizens are looking for innovative fishery-management approaches.

\section{California's situation}

Historically, California has had one of the world's most productive fisheries (Leet et al. 1992). Prevailing northwesterly winds and other factors combine to cause the upwelling of deep, cold nutrient-rich water to the sunlit surface. This leads to tremendous blooms of plankton (tiny plants and animals) that serve as the food base for the production of a large and diverse population of marine organisms. The intensity of this upwelling varies significantly, which makes it difficult to predict year-to-year variations in fish and shellfish populations (see page 36 ).

The sardine and tuna fisheries were California's most dominant during much of this century. Sardine landings grew to 700,000 tons during the 1930 s before collapsing in the late 1940s. The relative importance of the roles overfishing and changes in oceanographic conditions played in the collapse is still widely debated. After 40 years, sardine stocks have begun to recover and a small, conservatively managed fishery has resumed.

As the sardine fishery declined, the tropical tuna fleet expanded. Landings grew to more than 300 million pounds, worth more than all of the other fish landed in the state. However, by the early 1980 s, most of the tuna harvesting and processing industry had moved out of California. A combination of high labor costs, foreign competition 
and regulations related to dolphin protection resulted in the rapid shift of much of the fishing to the western Pacific and processing to American Samoa, Thailand and Puerto Rico. Between 1980 and 1985, the value of tropical tuna landings in California dropped tenfold, to $\$ 35$ million annually.

Since the early 1980 s, the nontuna fisheries have intensified and their value has doubled in real dollars. Much of this growth has been spurred by demand from the Pacific Rim for species such as sea urchin (see sidebar, right), herring, sablefish and other bottomfish. Important fisheries such as salmon, abalone, white seabass and some rockfishes have suffered serious declines. Loss of habitat (rivers and estuaries), poor water quality and overfishing are most often cited as reasons for the declines in abundance.

Marine recreational fishing is economically significant. California marine anglers annually land about 30 million fish and spend about $\$ 750$ million. Some species such as striped bass, sturgeon and abalone in Northern California are allocated solely for recreation.

\section{Fisheries management}

How are wild fish and shellfish populations managed? Two primary issues must be addressed. The first is to determine how many fish can be safely harvested each year and still sustain the population through reproduction and growth. The second challenge of the fish manager is to allocate the harvest among user groups such as commercial, recreational and Native American fishers. This also includes allocating some of the resource as forage for other fish, birds and marine mammals. Both issues are difficult and are a focus of much research and debate.

To determine what the sustainable rate of harvest could be requires estimates of the population size as well as variables such as growth rates, natural and fishing mortality rates, reproductive success and the effects of changes in the ocean environment on these variables. The unpredictable variability in ocean conditions and rapid

continued on p. 32

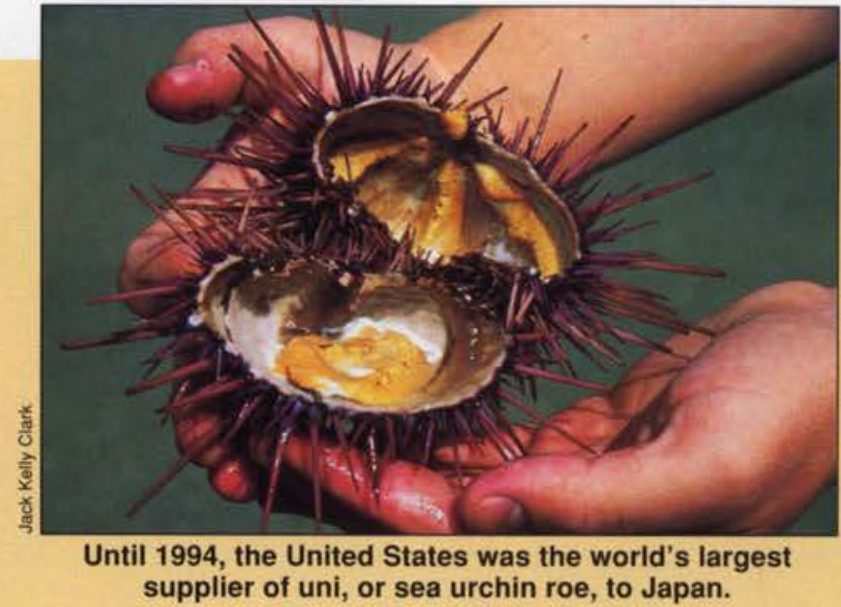

\section{Aquaculture boosts urchin roe production}

\section{Susan McBride}

Red sea urchins, with their hedgehoglike shells and five skeins of edible golden roe, are a gourmet treat, especially in Asia. Each year California divers harvest as many as $\mathbf{2 5}$ million pounds of the red sea urchins that many people find delicious and for which they are willing to pay dearly.

The commercial fishery for sea urchins in California began in the 1970s. However, the history of the sea urchin fishery dates back to the 1700 s, when sea otters, a major predator on sea urchins, were hunted nearly to extinction. With the demise of the sea otter, the sea urchin population grew unchecked.

In the 1970s, economic factors coincided to make the urchin fishery successful. Commercial air freight between the United States and Japan allowed sea urchin uni, which is consumed raw and fresh, to be flown to markets in Japan. Also, the dollar depreciated relative to the yen, making American goods, including sea urchin roe, less expensive to the Japanese (Muraoka 1990).

Sea urchins are harvested commercially worldwide, particularly in Japan, France, Chile and the United States. The United States has been the world's largest harvesting nation of sea urchins since 1988 and was the world's largest supplier of sea urchins and sea urchin roe to Japan until 1994 (Sonu 1995). However, harvests have plummeted in recent years, creating special incentives to the state's urchin divers and processors to use this valued resource efficiently.

One intriguing possibility emerged from early research, which showed that the yield of urchin roe is sensitive to food availability and may increase with preferred foods (Vadas 1977; Larson et al 1980; Lawrence et al 1997). In 1990, Sea Grant Marine Advisor Leigh Johnson demonstrated that urchins kept in seafloor enclosures could be "fattened up" if fed kelp. Gonad yield was measured as the wet weight of the gonads divided by the whole animal weight, and multiplied by 100 to give a percentage value called the "gonad index." Johnson found that over 2 months, the experimental "penned" animals had a gonad index almost double that of the controls $(16.1 \%$ vs $8.4 \%$ ) (Leighton and Johnson 1992).

These results were of great interest to the urchin industry, which had cooperated with Leigh Johnson in the studies, because selling fattened urchins in seasonal markets when supply is lowest and prices are highest would be an effective way to maximize resource value and improve market opportunities.

In response to industry requests, we initiated a series of experiments to determine whether red sea urchin could be held and fattened in culture systems on land. In addition to industry members, my collaborators include a number of professors and students at 


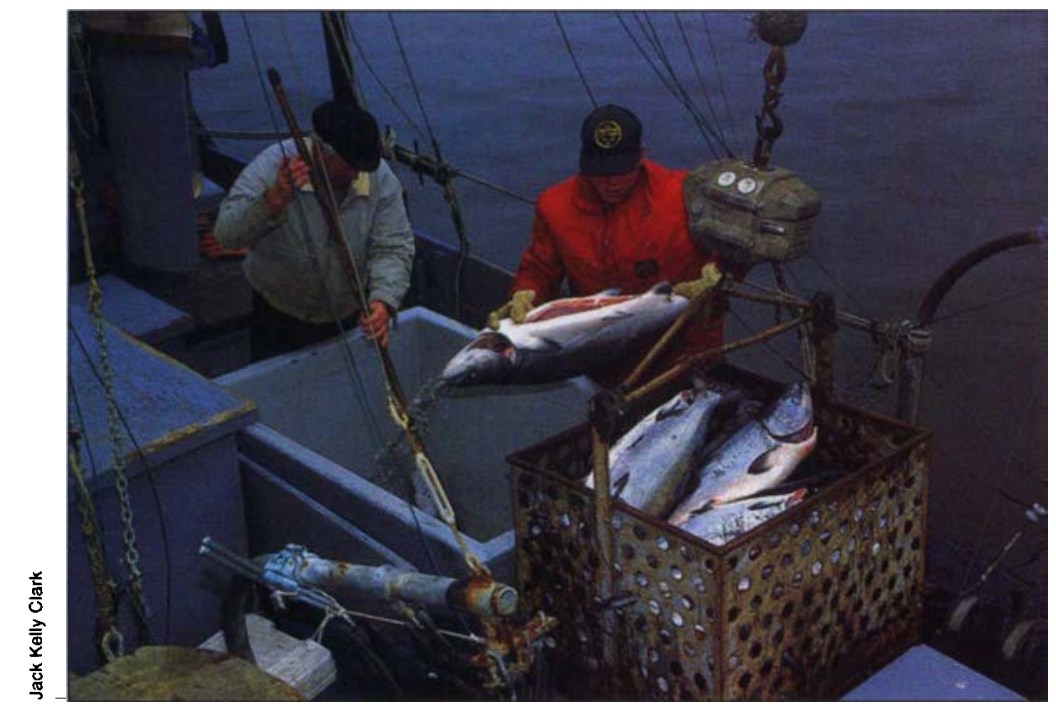

Fisheries managers use area closures, seasonal closures and quotas to protect depressed stocks of wild salmon. Along the North Coast these restrictions have caused hardship for the salmon industries.

\section{continued from $p .30$}

change in fishers' behavior and markets, as well as the interactions among species, further complicate this dynamic situation. Collecting, monitoring, analyzing and applying this information to manage fisheries and enforce regulations is an expensive process. In most cases, only the largest and most valuable fisheries are actively managed because the expense of managing many low-value fisheries is difficult to justify.

Traditionally, fishery managers have used several techniques to try to maintain biologically sustainable fisheries and limit mortality from fishing.

1. For some large fisheries, managers set an overall quota on the amount of fish taken in a year. Sometimes these quotas are divided up into shorter time periods (for example, weekly) in an attempt to spread the fishery out over a longer time period. In California, fish such as rockfish and sablefish are managed with quotas both for the entire season and with trip limits for each vessel. For recreational anglers, bag limits are a form of daily quota.

2. The type and amount of fishing gear used to catch the fish can be restricted to reduce the fishers' efficiency or to protect smaller fish sizes. Examples are larger mesh sizes for nets and barbless hooks.
3. Seasonal

closures and area closures can be used to protect young fish or to allow sexually mature fish to escape and reproduce. This is often done in salmon fisheries.

4. Size limits or net mesh sizes that allow small fish to escape are often implemented to allow fish and shellfish to reach reproductive maturity before harvest and to discourage harvest of less marketable individuals. Sea urchins, halibut and striped bass are California examples.

The second challenge, to allocate harvest rights among user groups, is further complicated by open access to the fishery by citizens and the tendency for fishery participants to increase their capability to catch fish before their competitors. Traditionally, two techniques are used.

1. Portions of the total allowable catch quota are allocated to different groups based on historical balance, benefit to the economy and political influence of the user groups. This can include recreational/commercial allocations as well as allocations to each segment (fishing gear type or location) of the fish harvesters.

2. Access to the fishery is limited to those with licenses, and the number of licenses is limited to try to give all licensees an opportunity to harvest an economically viable portion of the total harvest. Although this approach does limit access by outsiders, it maintains strong incentives to "race for the fish."

\section{Research to improve management}

In California, research funded by the California Sea Grant College System and agencies such as the National Marine Fisheries Service continues to address management-related problems. This work has focused on (1) increasing knowledge about the life histories of economically important species, (2) improving models used to estimate and predict population sizes to improve the manager's ability to set appropriate quotas, and (3) examination of alternative policies for managing fisheries (see page 33).

Sea Grant fisheries studies in the past 25 years have expanded the basic knowledge about California species, including sharks, squid, salmon, sturgeon, crab, anchovy, halibut, herring, abalone, sea urchins and many types of rockfish. As fisheries have intensified for these and other species, this information, combined with advances in modeling of populations, has been critical in setting some management policies. Sea Grant studies of fisheries policy have provided the state with a historical perspective about fisheries and critical economic information. Researchers have also explored alternative methods for controlling the rapid expansion of fishing effort in fully exploited fisheries.

\section{Fisheries in the new century}

Despite all of this experience and research, there is dissatisfaction worldwide with the state of fisheries management. Some of these concerns were reflected in the reauthorization of the Magnuson Act (the primary federal marine fisheries legislation) by Congress in 1996. Dramatic collapses of the New England/eastern Canada fisheries and some Pacific Northwest salmon stocks also spurred several major National Academy of Sciences studies exploring fishery problems and potential solutions. Fishery failures are seldom due to a lack of knowledge; they are more often due to a lack of management action even though resources are clearly declining.

Where do we go from here? In recent years several themes have emerged that are likely to strongly influence fisheries management in the 21st century (National Research Council 1994a).

1. A precautionary approach to setting annual total allowable catches is working its way into fisheries legislation around the world. This approach directs managers to select the more conservative (lower risk of overfishing) catch levels. If uncertainty is high, the continued on p. 35 

on the side of caution. In the past, catch quotas have often been increased when concerns about economic, social and political issues are combined with fish population estimates that have a high level of uncertainty.

2. Implementation of market-based management systems that issue exclusive

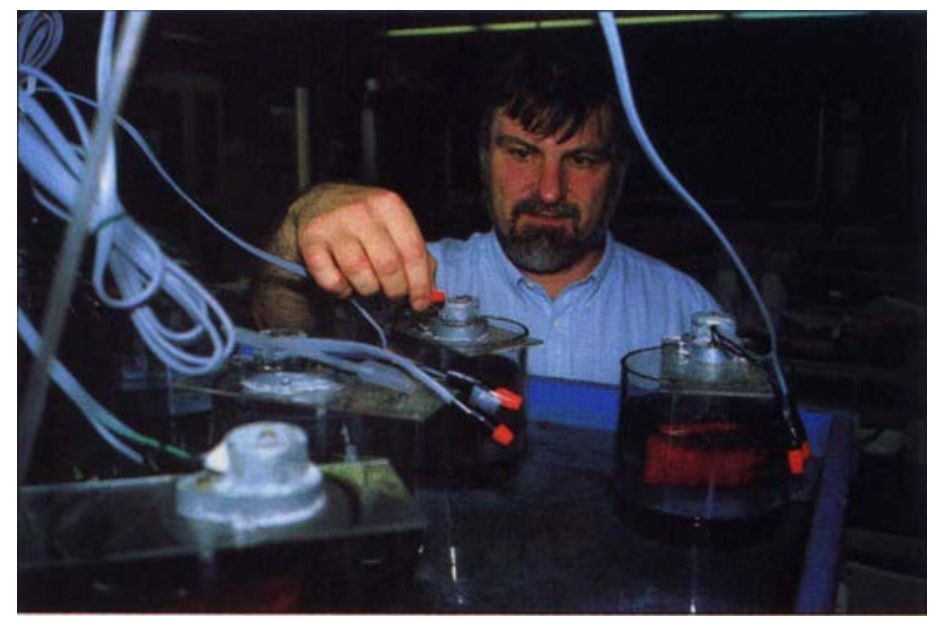

main stumbling block to widespread implementation of this approach is the risk and high cost of making a catastrophic mistake leading to a fishery collapse.

Fisheries management is a complex, multidisciplinary task. Increasing competition to meet the rising worldwide demand for seaproperty rights to participants to harvest a share of the total allowable catch is likely to increase. These individual transferable quota (ITQ) systems have been developed to lessen the "race for fish," overcapitalization and difficulty in controlling fishing effort that often occur under traditional management systems. ITQs generally motivate fishers to maximize their revenues (prices) and minimize their cost to maximize profits from their individual share of the catch.

Since the mid-1980s, ITQs have been implemented for many fisheries in New Zealand, Iceland, Australia, United States (halibut, sablefish, surf clams), Canada and other nations (Munro and Pitcher, 1996). These fisheries did change significantly under this system, and controversy about these changes recently led Congress to place a 4-year moratorium on the implementation of new ITQ systems in federally managed fisheries and to direct the National Academy of Sciences to study the issues. California Sea Grant has supported several studies related to ITQs.

3. Ecosystem management approaches, more closely associated with terrestrial systems, are being considered for coastal fisheries (National Research Council 1994b). These concepts include consideration of multispecies interactions, habitat types and condition and oceanic conditions. Fisheries have usually been managed on an individual species basis, and habitat issues are often separated from regulating fisheries.

One challenge with ecosystem management of ocean fisheries is the vast size of the ecosystem. It is easier to vi-

Sea Grant's Marine Fisheries Specialist Chris Dewees examines an experiment to culture sea urchins at the UC Bodega Marine Laboratory. Photo by John Stumbos.

sualize ecosystem management for a distinct geographic unit such as a watershed. New ecosystem management techniques to sustain fisheries resources may involve the use of spatial management, harvest refugia and replenishment zones (see page 41). In California, research into the feasibility of spatial management of sea urchins and rockfish currently is under way.

4. Community-based management of fisheries also may grow. This is often a community/government agreement (comanagement) that allows communities to manage fisheries within standards acceptable to government. For example, rural communities in western Alaska are allocated a share of the overall catch of some species. The communities decide how they want to manage the fishery locally, within government guidelines, with the goal of keeping the benefits in the community. The management of salmon by communities is another example of how local groups can take responsibility for habitat health, allocation of harvest and meeting escapement goals to sustain salmon populations.

\section{Adaptive management ap-} proaches, as described by Carl Walters and others (Walters 1986), involve trying different management approaches and then evaluating what happens. This experimental approach provides opportunities to learn about and compare management approaches. The food will further intensify fisheries issues. California's increasing population, competition for water, loss of aquatic and coastal habitat and water quality changes will increase the stress placed on fisheries resources. Wise, research-based policy decisions are needed to rebuild and sustain California's living marine resources.

C.M. Dewees is Marine Fisheries Specialist and Coordinator of the statewide Sea Grant Extension Program for Cooperative Extension, Department of Wildlife, Fish and Conservation Biology, UC Davis

\section{References}

Leet WS, Dewees CM, Haugen CW. 1992 California's living marine resources and their utilization. UCSGEP-92-12. Davis (CA): Sea Grant Extension Program.

Mangel M et al. 1996. Principles for the conservation of wild living resources. Ecol Applic 6(2):338-362.

McEvoy AF. 1986. The fisherman's problem: Ecology and law in the California fisheries, 1850-1980. Cambridge: Cambridge Univ Pr.

Moyle PB. 1993. Fish: An Enthusiast's Guide. Berkeley: Univ California Pr.

Munro GR, Pitcher TJ. 1996. Individual transferable quotas. Special issue of Rev Fish Biol Fisheries 6(1).

National Marine Fisheries Service. 1996. Our living oceans: Report on the status of U.S. living marine resources, 1995. Silver Spring (MD): National Oceanic and Atmospheric Administration.

National Research Council. 1994a. Improving the management of US marine fisheries. Washington, DC: Nat Acad Pr.

National Research Council. 1994b. Priorities for coastal ecosystem science. Washing ton, DC: Nat Acad Pr.

Walters C. 1986. Adaptive management of renewable resources. New York: MacMillan. 